TP Periodica Polytechnica Mechanical Engineering

\author{
61(3), pp. 213-224, 2017 \\ https://doi.org/10.3311/PPme.9747 \\ Creative Commons Attribution (i)
}

RESEARCH ARTICLE

\section{Vibration Analysis of Carbon Fiber Reinforced Laminated Composite Skin with Glass Honeycomb Sandwich Beam Using HSDT}

\author{
Mageshwaran Subramani ${ }^{1}$, Ananda Babu Arumugam ${ }^{1}$, \\ Manoharan Ramamoorthy ${ }^{1 *}$ \\ Received 15 July 2016; accepted after revision 01 March 2017
}

\begin{abstract}
In this paper, the vibration analysis of uniform laminated composite sandwich beam with a viscoelastic core was studied. The governing equation of motion of the laminated composite sandwich beam has been derived based on higher order shear deformation theory (HSDT) in finite element model (FEM). The developed finite element model has been validated in terms of natural frequencies with the experimental values and the available literature. Various parametric studies have been performed to examine the impact of the core thickness, ply orientation and aspect ratio of the uniform laminated composite sandwich beam in response to free vibration for various boundary conditions. From the results it was concluded that that natural frequencies could be increased with increasing the core thickness and decreased with increasing the aspect ratio.
\end{abstract}

\section{Keywords}

carbon fiber laminate, glass fiber honeycomb core, HSDT\& sandwich beam

\footnotetext{
${ }^{1}$ School of Mechanical Engineering, VIT University,

Vellore, Tamil Nadu, India

*Corresponding author, e-mail: rmanoharan@vit.ac.in
}

\section{Introduction}

Nowadays the demand for the sandwich structure is getting increased because of its high stiffness to the low weight ratio. It is also paved the attention of the researchers and scientist towards the sandwich structures. A Sandwich structure finds its place in wide range of applications because of its high stiffness and flexural rigidity especially in marine, aerospace and astronautics. Ibrahim Ozkol and AytacArikoglu [1] were made an investigation on vibration analysis of the uniform laminated composite sandwich beams with viscoelastic core using differential transform method. The governing equation of motion of sandwich beamwas formulated by Hamilton's principle and it was solved by differential transform method (DTM), Eigen value analysis method was used to generate and evaluate frequencies. Banerjee et al. [3] investigated the vibration characteristics of the viscoelastic material based asymmetric sandwich beam by using the dynamic stiffness model which was developed from the Timoshenko beam theory. Manoharan et al. [4] presented the finite element formulation of the magnetorheological (MR) fluid based sandwich beam. The governing equation of motion sandwich beam was formulated using finite element method. In this study it was concluded that the natural frequencies increased by increasing the intensity of the magnetic field irrespective to the boundary conditions. Allahverdizadeh et al. [5] was studied the dynamic behaviour of adaptive sandwich beams, where the middle layer as electro-rheological fluid (ERF) and constraining layers were fabricated by functionally graded materials (FGM). This study shows that the resonant frequencies and the amplitude of peak values have been decreased by increasing the thickness FGM at constant electric filed. From the results it was indicated that at a definite applied electric field, the Clamped-Clamped beam showed the higher resonant frequencies and the cantilever beam showed the least value among all end conditions. Xu and Qiu [6] studied the free vibration analysis and optimization method of composite lattice truss core sandwich beams. The partial differential governing equation of motion was developed by adopting the Hamilton principle which was based on Thimosenko and bernoullis beam theory and then the natural frequencies of the 
experimental model were compared with the finite element model. They concluded that the natural frequencies of the laminated composite sandwich beam were increased with increasing the core thickness, shear modulus and with decreasing the density. Arvin and Sadighi [7] performed a numerical investigation on free and forced vibration of composite sandwich beam and they focussed the comparative analysis between free and forced vibration. Also they developed the governing equation of motion by accomplishing the higher order theory and by assuming independent transverse displacement on each layer. Various parametric studies were performed in terms of natural frequencies, time response and loss factor of sandwich beam under various conditions. Zhen and Wanji [8] were performed a stability and vibrational analysis of composite structure using the various displacement theories and the theories used in the study was zig-zag theory (ZZT), Global-local higher-order theory (GLHT), First-order shear deformation theories (FSDT) and Global higher -order shear deformation theories (HSDT). The various application problems were solved and compared it with each otherin order to identify the effectiveness of the displacement theory. Howson and Zare [9] and Manalo et al. [10] were made an attempt to derive an effective stiffness matrix for sandwich beam with unequal faceplates were tested for flexural motion. The governing differential equation was developed from the closed form solution. In this study, Wittrick-Williams algorithm was adopted to predict the natural frequency of sandwich beam. The accuracy of the developed finite element method was confirmed by comparing the results of the previously published literatures. Malekzadeh et al. [11] were made an analysis of free vibration of sandwich beam by using the dynamic stiffness method and finite element methods. The governing equations of motion were formulated by using Hamilton's principle. Natural frequencies as well as mode shapes were determined by using Williams-Wittrick algorithm. After the validation of the results the effect of various characteristics parameters such as thickness, density and shear modulus of the honeycomb core for different boundary conditions on the first natural frequencies were studied. Parametric studies were performed and indicated that, by increasing the core/skin density ratios, there will be decrease in the first natural frequency. However by increasing the skin/core thickness ratios and the core shear modulus, the first natural frequency of the beam was increased with irrespective of the various boundary conditions. Nabi and Ganesan [12] were described the role of fiber orientation/ angle of the composite beams. They concluded that the natural frequencies of the composite sandwich beam were decreased by increasing of the fibre angle orientation with increase in the ratio of the length to height. Singh and Abdelnassar [13] investigated the forced vibration analysis of cross ply composite beam using third order shear deformation theory. Vinson and Sierakowski [14] determined the natural frequencies of the sandwich beam under the condition of simply supported at both ends and classical laminate theory (CLPT) was used for developing governing equation of motion. They concluded that the CLPT theory was suitable only for the thin section.

\section{Mathematical modelling of the honeycomb core laminated sandwich beam}

A uniform laminated composite sandwich beam with the viscoelastic core (Fig. 1) is considered for the numerical modeling. The higher order shear deformation theory (HSDT) is used for the developing the finite element formulation. The following assumptions are considered for deriving the governing equation as:

- Each ply obeys the hooks law.

- Body forces are being neglected.

- Each ply is bonded together and there is no slip.

- The core transmits only the transverse shear stresses.

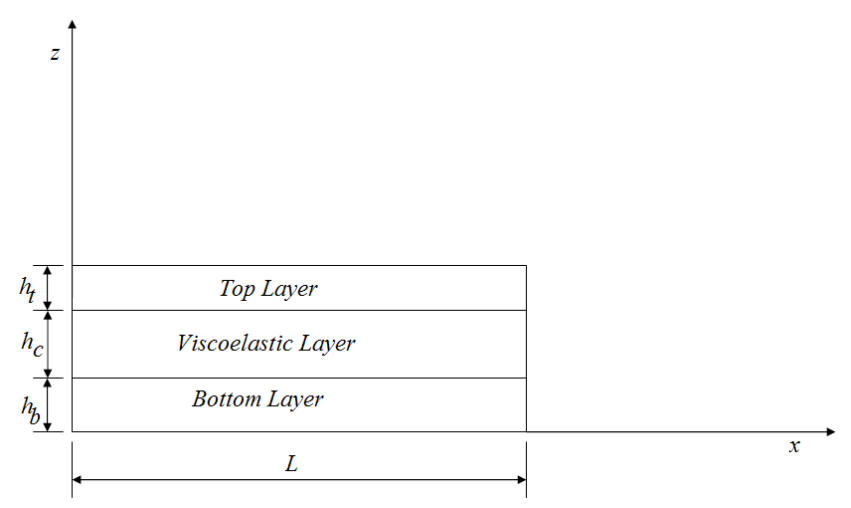

Fig. 1 Sandwich beam (where $L$ is the length of the sandwich beam, the top and bottom skin layer thickness are represented by $h_{t}$ and $h_{b}$ and the core layer thickness as indicated by $h_{c}$.)

\subsection{Formulation of constitute equation of the top and bottom laminate layers}

The derivation of the stress-strain relationship for the sandwich beam is represented by the co-ordinate axis $x, y$ and $z$.

The displacement field equation of the laminate is represented as

$$
\begin{gathered}
u(x, y, z)=u_{o}(x, y)+z \psi_{x}(x, y)+z^{2} \xi_{x}(x, y)+z^{3} \delta_{x}(x, y) \\
w(x, y, z)=w_{o}(x, y)
\end{gathered}
$$

Where $u$ is the displacement field along $x$-axis and $w$ is the transverse displacement. The displacement field along the $y$ direction is neglected. Shear correction factor $(k)$ is being considered in first order shear deformation theory (FSDT) but in higher order shear deformation theory (HSDT) the shear correction factor $(k)$ is not considered in finite element formulation. In this theory displacement field itself will provide the correlation as we are considering the higher order quadratic terms in the displacement field. It provides a better accurate 
results then FSDT. The number of independent variables in the displacement field is reduced from five to four by substituting the traction-free boundary condition.

$$
\begin{aligned}
& \sigma_{x z}(x, y . \pm h / 2, t)=0 \\
& \sigma_{y z}(x, y . \pm h / 2, t)=0
\end{aligned}
$$

After the execution of boundary condition the displacement field equation is get deduced into

$$
\begin{aligned}
& u=u_{0}+z\left[\psi_{x}-\frac{4 z^{2}}{3 h^{2}}\left(\frac{\partial w_{0}}{\partial x}+\psi_{x}\right)\right] \\
& \partial u \frac{\partial w_{o}}{\partial x}+\psi_{x}=\varphi_{x}
\end{aligned}
$$

$\psi_{x}$ is the transverse function with respect to $x$-axis.

Where $\varphi_{x}$ is the wrapping function it includes the transverse normal rotations with respect to the $x$-axis, the wrapping function is substituted in Eq. (3) for the perspective understanding.

$$
u=u_{0}+z\left[\psi_{x}-\frac{4 z^{2}}{3 h^{2}}\left(\varphi_{x}\right)\right]
$$

The displacement field equations of the top and bottom skin along $x$-axis on the mid-plane has been derived from the above equation and it is represented by $u_{t}$ and $u_{b}$ and the transverse displacement $w$ is uniform for the sandwich beam.

$$
\begin{gathered}
u_{t}=u_{o t}+z\left[\psi_{x}-\frac{4 z^{2}}{3 h^{2}}\left(\varphi_{x}\right)\right] \\
u_{b}=u_{o b}+z\left[\psi_{x}-\frac{4 z^{2}}{3 h^{2}}\left(\varphi_{x}\right)\right] \\
w=w_{o}
\end{gathered}
$$

The general non-linear strain displacement field associated with the displacement fields are derived and presented in Eqs. (8) and (9).

$$
\begin{gathered}
\epsilon_{x}=\epsilon_{x}^{0}+z k_{x}^{0}+z^{3} k_{x}^{2} \\
\epsilon_{x z}=\epsilon_{x z}^{0}+z^{2} k_{x z}^{2}
\end{gathered}
$$

Where

$$
\begin{aligned}
& \left(\epsilon_{x}^{0}\right)=\left(\frac{\partial u_{0}}{\partial x}\right)^{T} \\
& \left(K_{x}^{0}\right)=\left(\frac{\partial \psi_{x}}{\partial x}\right)^{T} \\
& \left(K_{x}^{2}\right)=\left(\frac{-4}{3 h^{2}} \frac{\partial \varphi_{x}}{\partial x}\right)^{T} \\
& \left(\epsilon_{x z}^{0}\right)=\left(\frac{\partial w_{0}}{\partial x}+\psi_{x}\right)^{T} \\
& \left(k_{x z}^{2}\right)=\left(-\frac{4}{h^{2}}\left(\phi_{x}\right)\right)^{T}
\end{aligned}
$$

Where $\in_{x}^{0}$ is the in-plane strain; $K_{x}^{0}, K_{x}^{2}$ are the mid-plane curvature and $\epsilon_{x z}^{0}$ is the transverse shear strain. The strain displacement fields are further simplified for the easy understanding. The general stress-strain relationship of the orthotropic lamina with respect to $x, y$ and $z$ axes are given by

$$
\begin{gathered}
\left\{\begin{array}{c}
\sigma_{x} \\
\sigma_{y} \\
\sigma_{x y}
\end{array}\right\}=\left[\begin{array}{lll}
Q_{11} & Q_{12} & Q_{13} \\
Q_{21} & Q_{22} & Q_{23} \\
Q_{31} & Q_{32} & Q_{33}
\end{array}\right]\left\{\begin{array}{c}
\epsilon_{x} \\
\epsilon_{y} \\
\epsilon_{x y}
\end{array}\right\} \\
\left\{\begin{array}{l}
\sigma_{X Z} \\
\sigma_{Y Z}
\end{array}\right\}=\left[\begin{array}{ll}
Q_{55} & Q_{54} \\
Q_{45} & Q_{44}
\end{array}\right]\left\{\begin{array}{c}
\epsilon_{x z} \\
\epsilon_{y z}
\end{array}\right\}
\end{gathered}
$$

where $Q_{i j}$ is the transformed material coefficient

$$
\begin{aligned}
& {\left[Q_{i j}\right]=\left[T_{1}\right]\left[\overline{Q_{i j}}\right]_{k 1}\left[T_{1}\right]} \\
& {\left[Q_{i j}\right]=\left[T_{2}\right]\left[\overline{Q_{i j}}\right]_{k 2}\left[T_{2}\right]}
\end{aligned}
$$

where $T_{1}$ and $T_{2}$ will be the transformed matrices and it represented in below

$$
\begin{aligned}
& T_{1}=\left[\begin{array}{ccc}
\cos ^{2} \theta & \sin ^{2} \theta & 2 \cos \theta \sin \theta \\
\sin ^{2} \theta & \cos ^{2} \theta & -2 \cos \theta \sin \theta \\
-\cos \theta \sin \theta & \cos \theta \sin \theta & \cos ^{2} \theta-\sin ^{2} \theta
\end{array}\right] \\
& T_{2}=\left[\begin{array}{cc}
\cos \theta & \sin \theta \\
-\sin \theta & \cos \theta
\end{array}\right]
\end{aligned}
$$

When the fibers are arranged in the varying sequence then the material properties in all the directions are varied and material properties on the fiber direction is obtained by using the the transformation matrix $T_{1}$ and $T_{2}$.

$$
\begin{aligned}
& {\left[Q_{i j}\right]_{k 1}=\left[\begin{array}{ccc}
\bar{Q}_{11} & \bar{Q}_{12} & 0 \\
\bar{Q}_{21} & \bar{Q}_{22} & 0 \\
0 & 0 & \bar{Q}_{66}
\end{array}\right]} \\
& {\left[Q_{i j}\right]_{k 2}=\left[\begin{array}{cc}
\bar{Q}_{55} & 0 \\
0 & \bar{Q}_{44}
\end{array}\right]}
\end{aligned}
$$

where stiffness relation coefficient related to the engineering constants are given below

$$
\begin{aligned}
& \bar{Q}_{11}=\frac{E_{1}}{\left(1-v_{12} v_{21}\right)}, \bar{Q}_{12}=\frac{v_{12} E_{2}}{\left(1-v_{12} v_{21}\right)}, \bar{Q}_{22}=\frac{E_{2}}{\left(1-v_{12} v_{21}\right)} \\
& \bar{Q}_{66}=G_{12}, \bar{Q}_{55}=G_{13}, \bar{Q}_{44}=G_{23}
\end{aligned}
$$

$E_{1}$ is the young's modulus along the fibre direction; $E_{2}$ and $E_{3}$ are young's modulus in matrix direction and it is same; $v_{12}$ $v_{21}$ are poison ratio and $G_{12}$ in-plane shear modulus.

The force, moment and higher order resultants are derived from the stress strain relation and the resultant stress field for the sandwich beam can be represented as 


$$
\begin{gathered}
\left\{\begin{array}{c}
N \\
M \\
P
\end{array}\right\}=\left[\begin{array}{lll}
A_{11} & B_{11} & E_{11} \\
B_{11} & D_{11} & F_{11} \\
E_{11} & F_{11} & H_{11}
\end{array}\right]\left\{\begin{array}{l}
\in_{x}^{0} \\
k_{x}^{0} \\
k_{x}^{2}
\end{array}\right\} \\
{\left[\begin{array}{l}
Q \\
R
\end{array}\right]=\left[\begin{array}{ll}
A_{11}^{s} & D_{11}^{s} \\
D_{11}^{s} & F_{11}^{s}
\end{array}\right]\left\{\begin{array}{c}
\epsilon_{x z}^{0} \\
k_{x z}^{2}
\end{array}\right\}}
\end{gathered}
$$

$N$ is normal force vector, $M$ is Bending moment force vector and $P, Q$ and $R$ are the higher order force terms. The stiffness matrices are derived as follows,

$$
\begin{aligned}
\left(A_{11}, B_{11}, D_{11}, E_{11}, F_{11}, H_{11}\right) & =\int_{-h / 2}^{-h / 2} Q_{11}\left(1, z, z^{2}, z^{3}, z^{4}, z^{6}\right) d z \\
\left(A_{11}^{s}, D_{11}^{s}, F_{11}^{s}\right) & =\int_{-h / 2}^{-h / 2} Q_{55}\left(1, z^{2}, z^{4}\right) d z
\end{aligned}
$$

\subsection{Formulation of constitute equation of the viscoelastic core layer}

Viscoelastic glass fiber honeycomb is considered as core in a laminated composite sandwich beam. Where the core transmits only the transverse shear stress based on that assumption the displacement field equation is derived. The formulation of shear strain energy of the viscoelastic core (glass honey comb) has been derived from the degrees of freedom of top and bottom skin under the shear to shear condition and Fig. 2 shows the schematic diagram of sandwich model on before and after deformation.

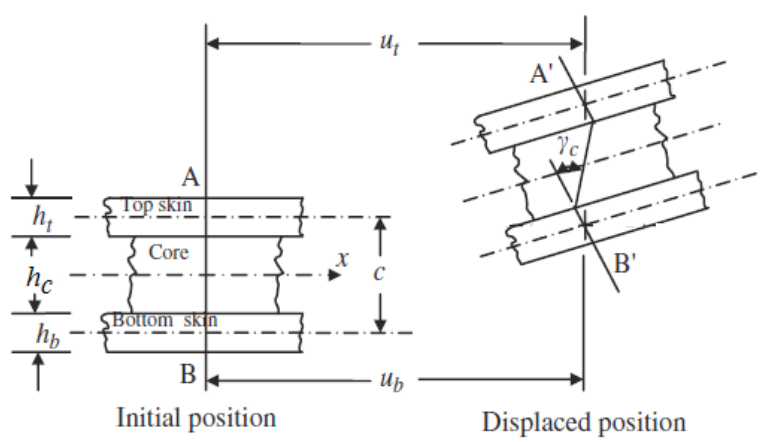

Fig. 2 Sandwich beam model of before and after deformation.

$$
\begin{gathered}
\gamma_{x z}=\frac{\partial u_{c}}{\partial z}+\frac{\partial w}{\partial x} \\
\frac{\partial u_{c}}{\partial z}=\frac{u_{o t}-u_{0 b}}{h_{c}}-\left(\frac{h_{t}+h_{b}}{2 h_{c}}\right) \psi_{x}+\left(\frac{h_{t}+h_{b}}{6 h_{c}}\right) \varphi_{x} \\
\gamma_{x z}=\frac{u_{o t}-u_{0 b}}{h_{c}}-\left(\frac{h_{t}+h_{b}}{2 h_{c}}\right) \psi_{x}+\left(\frac{h_{t}+h_{b}}{6 h_{c}}\right) \varphi_{x}+\frac{\partial w_{0}}{\partial x}
\end{gathered}
$$

\subsection{Formulation of strain energy equation of the laminated composite sandwich beam}

In general the strain energy expression is represented by

$$
U=\frac{1}{2} \int_{v} \sigma^{T}(\in) d v
$$

The skin layer exhibits both the axial and transverse deformation and the strain energy produced due to axial and transverse deformation is considered for developing the finite element model.

\subsubsection{Strain energy due to axial deformation on top and bottom skin}

Strain energy due to axial deformation on the top and bottom skin is represented in the matrix form for easy understanding

$U_{t}=\frac{1}{2} b \int_{0}^{l}\left[\frac{\partial u_{t}}{\partial x} \frac{\partial \psi_{x}}{\partial x}-\frac{4}{3 h^{2}} \frac{\partial \varphi_{x}}{\partial x}\right] \times\left[\begin{array}{lll}A_{11} & B_{11} & E_{11} \\ B_{11} & D_{11} & F_{11} \\ E_{11} & F_{11} & H_{11}\end{array}\right] \times\left[\begin{array}{c}\frac{\partial u_{t}}{\partial x} \\ \frac{\partial \psi_{x}}{\partial x} \\ -\frac{4}{3 h^{2}} \frac{\partial \varphi_{x}}{\partial x}\end{array}\right] d x$

$U_{b}=\frac{1}{2} b \int_{0}^{l}\left[\frac{\partial u_{b}}{\partial x} \frac{\partial \psi_{x}}{\partial x}-\frac{4}{3 h^{2}} \frac{\partial \varphi_{x}}{\partial x}\right] \times\left[\begin{array}{lll}A_{11} & B_{11} & E_{11} \\ B_{11} & D_{11} & F_{11} \\ E_{11} & F_{11} & H_{11}\end{array}\right] \times\left[\begin{array}{c}\frac{\partial u_{b}}{\partial x} \\ \frac{\partial \psi_{x}}{\partial x} \\ -\frac{4}{3 h^{2}} \frac{\partial \varphi_{x}}{\partial x}\end{array}\right] d x$

The strain energy due to axial deformation are represented in the Eq. (21) and (22) in matrix form with the respective degrees of freedom and stiffness matrix.

\subsubsection{Strain energy due to transverse deformation on top and bottom skin}

Strain energy due to the transverse deformation is depends on the transverse displacement $w$ and transverse rotation fields $U_{2}=\frac{1}{2} b \int_{0}^{l}\left[\frac{\partial w_{0}}{\partial x}+\psi_{x}-\frac{4}{h^{2}} \varphi_{x}\right] \times\left[\begin{array}{cc}A_{11}^{s} & D_{11}^{s} \\ D_{11}^{s} & F_{11}^{s}\end{array}\right] \times\left[\begin{array}{l}\frac{\partial w_{0}}{\partial x}+\psi_{x} \\ -\frac{4}{h^{2}} \varphi_{x}\end{array}\right] d x$

Strain energy $\left(U_{2}\right)$ is same for both top and bottom layers skin of sandwich beam as shearing will be same because of the symmetric structure of the laminated composite sandwich beam. 


\subsubsection{Strain energy of core}

Core exhibits only transverse shear stress. It transmits only the transverse shear deformation. Strain energy due to the transverse deformation has been derived based on the top and bottom displacement field equation.

$$
\begin{gathered}
U_{c}=\frac{1}{2} \int_{v} G_{x z} \gamma_{x z} *_{x z}{ }^{T} d x \\
\gamma_{x z}=\frac{u_{o t}-u_{o b}}{h_{c}}-\left(\frac{h_{t}+h_{b}}{2 h_{c}}\right) \psi_{x}+\left(\frac{h_{t}+h_{b}}{6 h_{c}}\right) \varphi_{x}+\frac{\partial w_{o}}{\partial x}
\end{gathered}
$$

\subsubsection{Total strain energy of Sandwich Beam}

Total strain energy of the sandwich beam is represented by $U_{T}$ and it is the summation of strain energy produced by the skin and the core. Strain energy due to the transverse deformation on the skin will remain same for the both top and bottom layer so it is added

$$
U_{T}=\left[U_{t}\right]+\left[U_{b}\right]+2 *\left[U_{2}\right]+\left[U_{c}\right]
$$

\subsection{Formulation of kinetic energy equation of the laminated composite sandwich beam}

Kinetic energy of the laminated composite sandwich beam is given by

$$
T=\frac{1}{2} \int_{v} m v^{2} d v
$$

\subsubsection{Kinetic energy of the top and bottom layer of the skin}

Kinetic energy for the top and bottom portion of the laminate has been derived based on the Lagrange method and it also represented in the matrix form with respective degrees of freedom. Kinetic energy equations of the top and bottom skin are denoted as $T_{t}$ and $T_{b}$.

Kinetic energy of the top skin is represented as

$T_{t}=\frac{1}{2} \int_{v} \rho\left[\begin{array}{llll}\frac{\partial u_{o t}}{\partial t} & \frac{\partial w_{o}}{\partial t} & \frac{\partial \psi_{x}}{\partial t} & \frac{\partial \varphi_{x}}{\partial t}\end{array}\right] *[I] *\left[\begin{array}{llll}\frac{\partial u_{o t}}{\partial t} & \frac{\partial w_{o}}{\partial t} & \frac{\partial \psi_{x}}{\partial t} & \frac{\partial \varphi_{x}}{\partial t}\end{array}\right]^{T} d x$

Kinetic energy of the bottom skin is represented as

$T_{t}=\frac{1}{2} \int_{v} \rho\left[\begin{array}{llll}\frac{\partial u_{o t}}{\partial t} & \frac{\partial w_{0}}{\partial t} & \frac{\partial \psi_{x}}{\partial t} & \frac{\partial \varphi_{x}}{\partial t}\end{array}\right] *[I] *\left[\begin{array}{llll}\frac{\partial u_{o t}}{\partial t} & \frac{\partial w_{0}}{\partial t} & \frac{\partial \psi_{x}}{\partial t} & \frac{\partial \varphi_{x}}{\partial t}\end{array}\right]^{T} d x$

Where $\rho$ is the density of the laminated composite sandwich beam and the $[I]$ matrix for laminated skin is given below

$$
\begin{gathered}
I=\left[\begin{array}{cccc}
I_{1} & 0 & I_{2} & -C_{1} * I_{4} \\
0 & I_{1} & 0 & 0 \\
I_{2} & 0 & I_{3} & -C_{1} * I_{5} \\
-C_{1} * I_{4} & 0 & -C_{1} * I_{5} & C_{1} * I_{7}
\end{array}\right] \\
I_{1}, I_{2}, I_{3}, I_{4}, I_{5}, I_{7},=\int_{-h / 2}^{-h / 2} \rho\left(1, z, z^{2}, z^{3}, z^{4}, z^{6}\right) d z
\end{gathered}
$$

\subsubsection{Kinetic energy of core}

The kinetic energy of the core due to the transverse deformation is given by

$$
\begin{aligned}
& T_{c}=\frac{1}{2} \int_{v} \rho_{c} z^{2} \frac{\gamma_{x z}{ }^{2}}{\partial t} d v \\
& T_{c}=\frac{1}{2} \frac{h_{c}^{3}}{12} \int_{v} \rho_{c} \frac{\gamma_{x z}^{2}}{\partial t} d x
\end{aligned}
$$

\subsubsection{Total kinetic energy of the sandwich beam}

Total kinetic energy of the sandwich beam is represented by $T$; It is sum of kinetic energies in top, bottom and core layer of the sandwich beam.

$$
T=\left[T_{c}\right]+\left[T_{t}\right]+\left[T_{b}\right]
$$

\section{Finite element formulation}

In the finite element model, a beam element with two nodes at each end is considered for modeling. Each node has five degrees of freedom and the respective stiffness and mass matrix has been derived based on the strain and kinetic energy formulation.

$$
\left\{\begin{array}{l}
u_{o} \\
w_{o} \\
\psi_{x} \\
\varphi_{x}
\end{array}\right\}=\left[\begin{array}{cccc}
N_{i} & 0 & 0 & 0 \\
0 & N_{i} & 0 & 0 \\
0 & 0 & N_{i} & 0 \\
0 & 0 & 0 & N_{i}
\end{array}\right]\left\{\begin{array}{c}
u_{o i} \\
w_{o i} \\
\psi_{x i} \\
\varphi_{x i}
\end{array}\right\}
$$

$\{u\}=N_{i}(x, y)$ where $\mathrm{i}=1,2$.

The shape functions $\mathrm{N}_{1}$ and $\mathrm{N}_{2}$ are

$$
N_{1}=\frac{(1-\varepsilon)}{2} ; \quad N_{2}=\frac{(1+\varepsilon)}{2}
$$

The relation between the strain and displacement field of the element is presented as

$$
\{X\}=[B]\{u\}
$$

$$
\{X\}=\left[\begin{array}{lll}
\frac{\partial u}{\partial x} & \frac{\partial \psi_{x}}{\partial x} & -\frac{4}{3 h^{2}} \frac{\partial \varphi_{x}}{\partial x}
\end{array}\right]^{T}
$$




\subsection{Derivation of element stiffness matrix}

The stiffness matrix of the sandwich beam has been derived from the strain energy of the sandwich beam. In general the strain energy of the laminate skin is represented as

$$
\begin{gathered}
U=\frac{1}{2} b\left(\int_{0}^{l}\{d\}^{T}[B(x, y)]^{T} *\left[\begin{array}{lll}
A_{11} & B_{11} & E_{11} \\
B_{11} & D_{11} & F_{11} \\
E_{11} & F_{11} & H_{11}
\end{array}\right] *[B(x, y)] *\{d\}\right) d x \\
U=\frac{1}{2} b\left(\int_{0}^{l}\{d\}^{T}\left[k_{e}\right] *\{d\}\right) d x
\end{gathered}
$$

Stiffness matrix of the laminate skin due to axial deformation

$$
\begin{aligned}
K_{e t} & =b\left(\int_{-a}^{a}\left[B_{t}(x, y)\right]^{T}\left[\begin{array}{lll}
A_{11} & B_{11} & E_{11} \\
B_{11} & D_{11} & F_{11} \\
E_{11} & F_{11} & H_{11}
\end{array}\right]\left[B_{t}(x, y)\right]\right) d x \\
K_{e b} & =b\left(\int_{-a}^{a}\left[B_{b}(x, y)\right]^{T}\left[\begin{array}{lll}
A_{11} & B_{11} & E_{11} \\
B_{11} & D_{11} & F_{11} \\
E_{11} & F_{11} & H_{11}
\end{array}\right]\left[B_{b}(x, y)\right]\right) d x
\end{aligned}
$$

where stiffness matrix of the top and bottom skin is represented as $K_{e t}, K_{e b}$ and the strain displacement matrix varied with the degrees of freedom.

Similarly the stiffness element for transverse deformation and core are also derived.

Stiffness matrix of skin due to transverse deformation

$$
k_{s}=b \int_{-a}^{a}\left[B_{s}(x, y)\right]^{T}\left[\begin{array}{cc}
A_{11}^{s} & D_{11}^{s} \\
D_{11}^{s} & F_{11}^{s}
\end{array}\right]\left[B_{s}(x, y)\right] d x
$$

Stiffness matrix of core

$$
k_{c}=b \int_{-a}^{a}\left[B_{c}(x, y)\right]^{T} *\left[G_{x z}\right] *\left[B_{c}(x, y)\right] d x
$$

Total stiffness matrix

Total stiffness matrix of the sandwich beam is represented by $k_{T}$ and it is the summation of stiffness matrix produced by the skin and the core. Stiffness matrix derived from the transverse strain energy will remain same for the both top and bottom layer so it is added.

$$
\left[k_{T}\right]=\left[k_{e t}\right]+\left[k_{e b}\right]+2\left[k_{s}\right]+\left[k_{c}\right]
$$

\subsection{Derivation of element mass matrix}

The mass matrix of the sandwich beam has been derived from the kinetic energy.

$$
\begin{aligned}
& T=\frac{1}{2} b \int_{0}^{l} \sum\{d\}^{T} *\left[N_{i}(x, y)\right]^{T} *[I] *\left[N_{i}(x, y)\right]\{d\} d x \\
& T=\frac{1}{2}\{d\}^{T}\left[m_{e}\right]\{d\}
\end{aligned}
$$

From the above equation the element mass matrix has been derived.

Mass matrix of skin layer

$$
m_{e}=b \int_{0}^{l} \sum\left[N_{i}(x, y)\right]^{T} *[I] *\left[N_{i}(x, y)\right] d x
$$

Mass matrices for the top and bottom skin layer are varying with respective to shape functions and degrees of freedom.

Mass matrix of core

The mass matrix of the core layer is represented by

$$
\begin{gathered}
T_{c}=b \frac{h_{c}^{3}}{12} \int_{v} \rho_{c} \frac{\partial \gamma_{x z}^{2}}{\partial t} d x \\
m_{c}=b \frac{h_{c}^{3}}{12} \int_{0}^{l} \sum\left[N_{i}(x, y)\right]^{T} *[I] *\left[N_{i}(x, y)\right] d x
\end{gathered}
$$

Total mass matrix of the element

$$
\left[m_{T}\right]=\left[m_{c}\right]+\left[m_{e t}\right]+\left[m_{e b}\right]
$$

The governing equations of motion for the laminated honeycomb sandwich beam in the finite element form can be obtained as

$$
\left[m_{T}\right]\{\ddot{d}\}+\left[k_{T}\right]\{d\}=0
$$

Where $\left[k_{T}\right]$ and $\left[m_{T}\right]$ are element stiffness and mass matrix of the sandwich beam and $d$ is the displacement field vector. The stiffness and mass matrices are assembled together for a whole number of elements using MATLAB ${ }^{\circledR}$ software and it yields governing equation for the sandwich beam.

$$
[M]\{\ddot{d}\}+[K]\{d\}=0
$$

Where system mass and stiffness matrix are represented as $[\mathrm{K}]$ and $[\mathrm{M}]$.

\section{Convergence Result}

A numerical simulation is performed to study the effect of number of discretization elements in the sandwich beam of length $300 \mathrm{~mm}$ and breadth $50 \mathrm{~mm}$ under the condition of clamped free for the same material properties given in Table 6 . Convergence study was performed by varying the meshing element size from 10 to 100 . Initially the numerical simulation started with meshing element size of 10 and then it has been increased at an equal interval. From the Table 2, it could be observed that the first three natural frequencies of the laminated composite sandwich beam are not varying after the meshing element size of 60 . 


\section{Validation of the developed finite element \\ formulation}

\subsection{Analytical validation}

The simulation is performed with the material and geometrical properties by Nayak et al. [2] under the simply supported beam condition. The material properties of the sandwich beam are $l=0.9144 \mathrm{~m}$, width, $b=25.4 \mathrm{~mm}$; core thickness, $h_{c}=12.7 \mathrm{~mm}$; skin thickness, $h_{t}=h_{b}=0.4572 \mathrm{~mm}, E_{t}=E_{b}=68.9$ $\mathrm{GPa}, G_{c}=82.68 \mathrm{MPa}$, density of the top and bottom skins, $\rho_{t}=\rho_{b}=2680 \mathrm{~kg} / \mathrm{m}^{3}$ and $\rho_{c}=32.8 \mathrm{~kg} / \mathrm{m}^{3}$

The natural frequencies of first four modes are determined and represented in Table 1, It is found that there is a good agreement of results are observed between current FEM analysis and those of Nayak et al. [2].

Table 1 Validation of natural frequencies under the condition of simply supported at both ends.

\begin{tabular}{llll}
\hline \multirow{2}{*}{$\begin{array}{l}\text { Mode } \\
\text { shapes }\end{array}$} & \multicolumn{3}{c}{ Frequencies (Hz) } \\
\cline { 2 - 3 } & Nayak et al. [2] & Present (FEM) & \\
\hline 1 & 57.136 & 60.662 & 5.54 \\
2 & 219.585 & 232.76 & 5.83 \\
3 & 465.173 & 492.27 & 5.501 \\
4 & 768.178 & 812.29 & 5.41 \\
\hline
\end{tabular}

The validity of the present finite element model is further examined by comparing the natural frequencies under the clamped free condition and then the simulation is performed by considering the material and geometrical properties of the specimen; $\mathrm{Et}=\mathrm{Eb}=72 \mathrm{GPa}, \rho \mathrm{t}=\rho \mathrm{b}=2700 \mathrm{~kg} / \mathrm{m} 3, \rho \mathrm{c}=$ $950 \mathrm{~kg} / \mathrm{m} 3, \mathrm{Gc}=0.5 \mathrm{MPa}, 1=500 \mathrm{~mm}, \mathrm{~b}=25 \mathrm{~mm}, \mathrm{ht}=\mathrm{hb}=$ $2 \mathrm{~mm}$, and $\mathrm{hc}=18 \mathrm{~mm}$. The results presented in the Table 3 , the outcomes shown that there is a good agreement between the results. The effectiveness of the present finite element model is also further examined by comparing the natural frequencies under the condition of clamped free at both ends with those derived by Howson and Zare [9]. The material properties used for simulation $\mathrm{l}=0.9144 \mathrm{~m}$, width, $\mathrm{b}=25.4 \mathrm{~mm}$; core thickness, $\mathrm{hc}=12.7 \mathrm{~mm}$; skin thickness, $\mathrm{ht}=\mathrm{hb}=0.4572$ $\mathrm{mm}, \mathrm{Et}=\mathrm{Eb}=68.9 \mathrm{GPa}, \mathrm{Gc}=82.68 \mathrm{MPa}$, density of skin, $\rho \mathrm{t}=\rho \mathrm{b}=2680 \mathrm{~kg} / \mathrm{m} 3$ and $\rho \mathrm{c}=328 \mathrm{~kg} / \mathrm{m} 3$. The first six natural frequencies are evaluated under the clamed-free end condition. From Table 4 it can be seen that there is a good agreement of present finite element formulation and those of Howson and Zare [9].

The validity of the developed finite element model is further examined with those of Zhou et al. [15]. The simulation is performed with the material and geometrical properties; $l$ $=150 \mathrm{~mm}$, width, $b=0.1 \mathrm{~m}$; core thickness, $h_{c}=2 \mathrm{~mm}$; skin thickness, $h_{t}=h_{b}=0.1 \mathrm{~mm}, E_{t}=E_{b}=72 \mathrm{GPa}, G_{c}=0.6208 \mathrm{MPa}$, density of skins are, $\rho_{t}=\rho_{b}=2700 \mathrm{~kg} / \mathrm{m}^{3}$ and $\rho_{b}=1100 \mathrm{~kg} / \mathrm{m}^{3}$ under the condition of simply supported and from the Table 5, it is again conformed that the effectiveness of the present finite element formulation.

\subsection{Experimental Validation}

The developed finite element formulation is also validated by the results in terms of natural frequencies with experiments. In this study the Uniform laminated composite sandwich beam is fabricated of length $400 \mathrm{~mm}$, width of $50 \mathrm{~mm}$ and thickness of $6 \mathrm{~mm}$. A hand-layup technique is used for fabricating the laminate. Where the thickness of the top and bottom laminate is $1 \mathrm{~mm}$. Laminate was fabricated using bidirectional inter carbon fibre, adralite, (LY556) Epoxy resin with HY951 hardener. The stacking sequence of the laminate skins in the sandwich beam was $\left[0^{\circ} / 90^{\circ}\right] \mathrm{s}$ and the same stacking sequence was followed for both top and bottom skin laminate. The thickness of the each ply is $0.2 \mathrm{~mm}$ and glass fiber honeycomb core was used in this study and the material properties of the sandwich beam are given in the Table 6. The schematic diagram and experimental setup as shown in the Fig. 3 and a special fixture was used for holding the specimen. Roving hammer technique (impulse force hammer - 086C03) was used to produce the excitations in the specimen. A single axis accelerometer, oriented along the z-axis was placed above the specimen to measure the acceleration signals. The acceleration signals are converted into frequency function response by using four channel data acquisition system (Model No. ATA-DAQ042451). From the response the natural frequencies at various modes was determined by using the DEWES 7.1.1 software under various boundary conditions. Experiments are also performed and the results are compared for the validation.

Table 2 Convergence results under clamped free condition

\begin{tabular}{|c|c|c|c|c|c|c|c|c|c|c|}
\hline \multirow{2}{*}{$\frac{\text { Modes }}{\text { No.of meshing element }}$} & \multicolumn{10}{|c|}{ Frequencies $(\mathrm{Hz})$} \\
\hline & 10 & 20 & 30 & 40 & 50 & 60 & 70 & 80 & 90 & 100 \\
\hline Mode 1 & 76 & 75 & 74 & 74 & 74 & 74 & 74 & 74 & 74 & 74 \\
\hline Mode 2 & 442 & 430 & 428 & 427 & 427 & 427 & 427 & 426 & 426 & 426 \\
\hline Mode 3 & 1137 & 1085 & 1076 & 1072 & 1071 & 1070 & 1069 & 1069 & 1069 & 1069 \\
\hline Mode 4 & 2043 & 1895 & 1869 & 1860 & 1855 & 1853 & 1852 & 1851 & 1850 & 1850 \\
\hline Mode 5 & 3141 & 2808 & 2750 & 2730 & 2721 & 2715 & 2712 & 2710 & 2709 & 2709 \\
\hline
\end{tabular}


Table 3 Validation of present FEM results in-terms of natural frequencies with Nayak et al. [2] under the clamped free condition.

\begin{tabular}{llll}
\hline \multirow{2}{*}{$\begin{array}{l}\text { Mode } \\
\text { shapes }\end{array}$} & \multicolumn{2}{c}{ Frequencies (Hz) } & \% Deviation \\
\cline { 2 - 3 } & Nayak et al. [2] & Present FEM & \\
\hline 1 & 12.308 & 12.311 & 0.02 \\
2 & 43.204 & 44.261 & 2.3 \\
3 & 94.427 & 94.179 & 0.2 \\
\hline
\end{tabular}

Table 4 Validation of present FEM results in-terms natural frequencies with Howson and Zare [9] under the clamped- free condition.

\begin{tabular}{llll}
\hline \multirow{2}{*}{$\begin{array}{l}\text { Mode } \\
\text { shapes }\end{array}$} & \multicolumn{2}{c}{ Frequencies (Hz) } & \multirow{2}{*}{ \% Deviation } \\
\cline { 2 - 3 } & Howson and Zare [9] & Present analysis (FEM) & \\
\hline 1 & 33 & 35 & 5 \\
2 & 198 & 208 & 4 \\
3 & 512 & 535 & 4 \\
4 & 907 & 945 & 4 \\
5 & 1349 & 1405 & 3 \\
6 & 1815 & 1868 & 2 \\
\hline
\end{tabular}

Table 5 Validation of natural frequencies under the condition of simply supported at both the ends

\begin{tabular}{llll}
\hline \multirow{2}{*}{$\begin{array}{l}\text { Mode } \\
\text { shapes }\end{array}$} & \multicolumn{2}{c}{ Frequencies (Hz) } & \multirow{2}{*}{ \% Deviation } \\
\cline { 2 - 3 } & Zhou et al. [15] & Present analysis (FEM) & \\
\hline 1 & 68.816 & 72 & 5.55 \\
2 & 152.441 & 147 & 3.28 \\
3 & 225.08 & 226 & 0.4 \\
\hline
\end{tabular}

Table 6 Material properties of the laminated composite sandwich beam

\begin{tabular}{ll}
\hline Laminate thickness $\left(\mathrm{h}_{\mathrm{t}}{ }_{\mathrm{b}}\right)$ & $2 \mathrm{~mm}$ \\
Laminate young's modulus $\left(\mathrm{E}_{\mathrm{t}, \mathrm{b}}\right)$ & $72 \mathrm{G} \mathrm{Pa}$ \\
Laminate density $\left(\rho_{\mathrm{t}, \mathrm{b}}\right)$ & $1831 \mathrm{~kg} / \mathrm{m}^{3}$ \\
Core thickness $\left(\mathrm{h}_{\mathrm{c}}\right)$ & $3 \mathrm{~mm}$ \\
Core density $\left(\rho_{\mathrm{c}}\right)$ & $48 \mathrm{~kg} / \mathrm{m}^{3}$ \\
Core shear modulus $\left(\mathrm{G}_{\mathrm{c}}\right)$ & $131 \mathrm{MPa}$ \\
\hline
\end{tabular}

The present finite element model for the laminated composite sandwich beam is validated with the experimental results in terms of natural frequencies under the Clamped-Free(C-F) condition. The material and geometrical properties were considered for the simulations as shown in Table 6. From Table 7 it has been noticed that a good matching results was obtained between experimental and analytical values. From the comparison study, effectiveness of the derived finite element formulation is demonstrated.

The effectiveness of the present FEM is further verified by performing the experimentations under the conditions of clamped at both ends. From Table 8, a good agreement of results was observed between the present finite element formulation

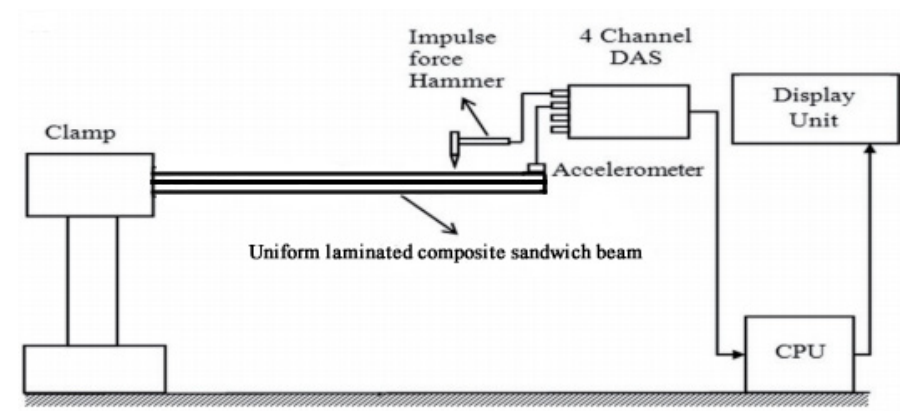

(a)

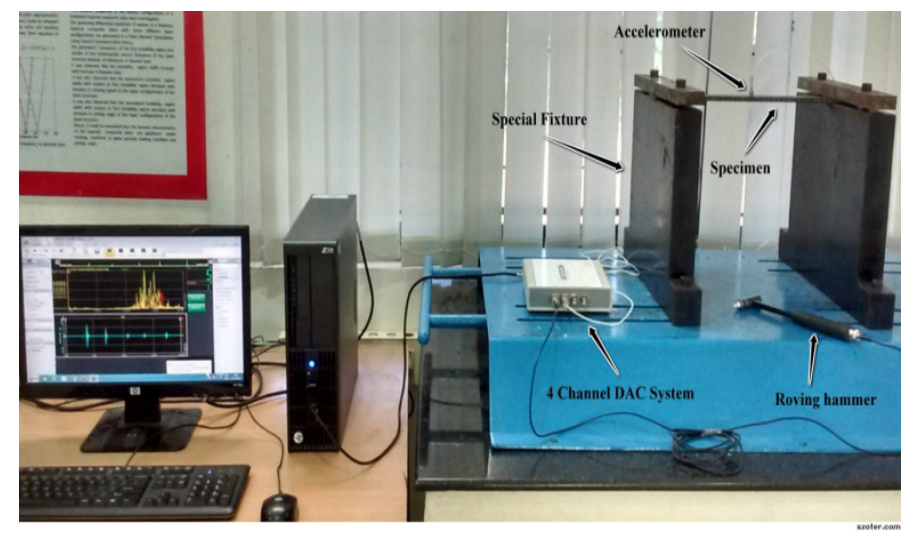

(b)

Fig. 3 Experimental Setup: (a) block diagram of experimental setup and (b) photograph of experimental setup.

Table 7 Comparison of natural frequencies of the laminated composite sandwich beam under the clamped-free condition.

\begin{tabular}{llll}
\hline \multirow{2}{*}{$\begin{array}{l}\text { Mode } \\
\text { shapes }\end{array}$} & \multicolumn{2}{c}{ Frequencies (Hz) } & \multirow{2}{*}{ \% Deviation } \\
\cline { 2 - 3 } & Experiment Results & Present FEM Results & \\
\hline 1 & 74 & 74.471 & 0.01 \\
2 & 446 & 427.99 & 4 \\
3 & 1146 & 1069.5 & 6 \\
\hline
\end{tabular}

Table 8 Comparison of natural frequencies of the laminated composite sandwich beam under the condition of clamped at both ends.

\begin{tabular}{llll}
\hline \multirow{2}{*}{$\begin{array}{l}\text { Mode } \\
\text { shapes }\end{array}$} & \multicolumn{2}{c}{ Frequencies (Hz) } & \% Deviation \\
\cline { 2 - 3 } & Experimental Results & Present FEM Results & \\
\hline 1 & 394 & 415.07 & 5 \\
2 & 1019 & 1006.6 & 1 \\
3 & 1751 & 1749.1 & 0.1 \\
\hline
\end{tabular}

and experimental in-terms of natural frequencies and it was found within the acceptable variation limit.

\section{Result and discussion}

The dynamic properties of a laminated composite sandwich beam are strongly influenced by the viscoelastic core. The vibration analysis of the uniform laminated composite sandwich beam with the glass fiber core was performed and the natural frequencies were determined. The natural frequencies of 
a sandwich beam are greatly influenced by the characteristics parameter such as core thickness, number of plies, orientation of plies, aspect ratio and various boundary conditions. The parametric studies were performed with material properties are given in the Table 6 and geometric dimensions of length $l=400$ $\mathrm{mm}$ and width $b=50 \mathrm{~mm}$.

\subsection{Influence of boundary conditions}

The effect of the boundary conditions on natural frequencies of sandwich beam was investigated for the given configuration. Where the laminated composite sandwich beam model is simulated under the various boundary conditions such as simply supported at each ends (S-S), clamped - clamped (C-C) and clamped free $(\mathrm{C}-\mathrm{F})$ end conditions. From the Table 9 it could be observed that the higher natural frequencies are obtained at clamped-clamped end conditions and smaller natural frequencies are obtained at clamped free end conditions.

Table 9 Influence of sandwich beam under various boundary conditions

\begin{tabular}{llll}
\hline \multirow{2}{*}{$\begin{array}{l}\text { Mode } \\
\text { Shapes }\end{array}$} & \multicolumn{3}{c}{ Frequencies $(\mathrm{Hz})$} \\
\cline { 2 - 4 } & S-S & C-F & C-C \\
\hline 1 & 409 & 74.471 & 415.07 \\
2 & 981 & 427.99 & 1006.6 \\
3 & 1694 & 1069.5 & 1749.1 \\
\hline
\end{tabular}

\subsection{Influence of core thickness}

The effect of laminated composite sandwich beam is studied by varying the core thickness under clamped free end conditions. From the Table 10 results it has been recognized that the natural frequencies at each mode is increased with increasing the thickness of the core layer.

Table 10 Influence of laminated composite sandwich beam core thickness on natural frequencies under clamped free condition

\begin{tabular}{lllll}
\hline \multirow{2}{*}{$\begin{array}{c}\text { Thickness } \\
(\mathrm{mm})\end{array}$} & \multicolumn{4}{c}{ Frequencies $(\mathrm{Hz})$} \\
\cline { 2 - 5 } & Mode 1 & Mode 2 & Mode 3 & Mode 4 \\
\hline 3 & 74 & 427 & 1069 & 1868 \\
4 & 89 & 502 & 1237 & 2096 \\
5 & 104 & 573 & 1376 & 2301 \\
6 & 119 & 638 & 1508 & 2488 \\
\hline
\end{tabular}

\subsection{Influence of aspect ratio}

A numerical simulation is performed to investigate the effect of aspect ratio on natural frequencies. Aspect ratio is the ratio of length to thickness sandwich beam. In this study length is kept constant and the thickness of the sandwich beam is diversed to obtain the different aspect ratio. The simulation of the FEM is executed in clamped free condition and the results are presented in the Table 11. From the results it has been noticed that natural frequencies of the sandwich beam at the entire mode is decreased with increasing the aspect ratio.

Table 11 Influence of aspect ratio on natural frequencies of sandwich beam under the clamped free condition

\begin{tabular}{lllll}
\hline \multirow{2}{*}{ Aspect ratio } & \multicolumn{4}{c}{ Frequencies (Hz) } \\
\cline { 2 - 5 } & Mode 1 & Mode 2 & Mode 3 & Mode 4 \\
\hline 30 & 118 & 592 & 1404 & 2352 \\
40 & 89 & 496 & 1207 & 2051 \\
50 & 76 & 436 & 1090 & 1888 \\
\hline
\end{tabular}

\section{Conclusions}

In this study, the free vibration analysis of laminated composite sandwich beam was performed and various characteristics parameters were investigated. Higher order shear deformation theory (HSDT) was used for formulating the governing equation of motion in the finite element model. The validity of finite element model was demonstrated by comparing the results in terms the natural frequencies with the experiment values and in available literature. Various parametric studies were performed to study the effect of core thickness, aspect ratio and boundary conditions and it was shown that natural frequencies of uniform laminated sandwich beam is increased with increasing the thickness of the core. Natural frequencies of uniform laminated sandwich beam are also decreased with increasing the aspect ratio of the sandwich beam. The higher natural frequencies are obtained at clamped-clamped end conditions and smaller natural frequencies are obtained at clamped free end conditions and it is demonstrated by both experimental as well as analytical. Therefore it could be concluded that the natural frequencies of the laminated composite sandwich beam was influenced by varying the core thickness, aspect ratio and boundary conditions.

\section{References}

[1] Arikoglu, A., Ozkol, I. "Vibration analysis of composite sandwich beams with viscoelastic core by using differential transform method." Composite Structures. 32(12), pp. 3031-3039. 2010. https://doi.org/10.1016/j.compstruct.2010.05.022

[2] Nayak, B., Dwivedy, S. K., Murthy, K. S. K. R. "Dynamic analysis of magnetorheological elastomer-based sandwich beam with conductive skins under various boundary conditions." Journal of Sound and Vibration. 330(9), pp. 1837-1859. 2011. https://doi.org/10.1016/j.jsv.2010.10.041

[3] Banerjee, J. R., Cheung, C. W., Morishima, R., Perera, M., Njuguna, J. "Free vibration of a three-layered sandwich beam using the dynamic stiffness method and experiment." International Journal of Solids and Structures. 44(22), pp. 7543-7563. 2007. https://doi.org/10.1016/j.ijsolstr.2007.04.024

[4] Manoharan, R., Vasudevan, R., Jeevanantham, A. K. "Dynamic characterization of a laminated composite magnetorheological fluid sandwich plate." Smart Materials and Structures. 23(2), Article number: 025022, 2014. https://doi.org/10.1088/0964-1726/23/2/025022 
[5] Allahverdizadeh, A., Mahjoob, M. J., Eshraghi, I., Nasrollahzadeh, N. "On the vibration behavior of functionally graded electrorheological sandwich beams." International Journal of Mechanical Sciences. 70, pp. 130-139, 2013.

https://doi.org/10.1016/j.ijmecsci.2013.02.011

[6] Xu, M., Qiu, Z. "Free vibration analysis and optimization of composite lattice truss core sandwich beams with interval parameters." Composite Structures. 106, pp. 85-95. 2013.

https://doi.org/10.1016/j.compstruct.2013.05.048

[7] Arvin, H., Sadighi, M., Ohadi, A. R. "A numerical study of free and forced vibration of composite sandwich beam with viscoelastic core." Composite Structures. 92(4), pp. 996-1008. 2010. https://doi.org/10.1016/j.compstruct.2009.09.047

[8] Zhen, W., Wanji, C. "An assessment of several displacement-based theories for the vibration and stability analysis of laminated composite and sandwich beams." Composite Structures. 84(4), pp. 337-349. 2008. https://doi.org/10.1016/j.compstruct.2007.10.005

[9] Howson, W. P., Zare, A. "Exact dynamic stiffness matrix for flexural vibration of three-layered sandwich beams." Journal of Sound and Vibration. 282(3-5), pp. 753-767. 2005.

https://doi.org/10.1016/j.jsv.2004.03.045

[10] Manalo, A. C., Aravinthan, T., Karunasena, W. "Flexural behaviour of glue-laminated fibre composite sandwich beams." Composite Structures. 92(11), pp. 2703-2711. 2010.

https://doi.org/10.1016/j.compstruct.2010.03.006
[11] Khalili, S. M. R., Nemati, N., Malekzadeh,. K., Damanpack, A. R. "Free vibration analysis of sandwich beams using improved dynamic stiffness method." Composite Structures. 92(2), pp. 387-394. 2010. https://doi.org/10.1016/j.compstruct.2009.08.020

[12] Mohamed Nabi, S., Gaesan, N. "A generalized element for the free vibration analysis of composite beams." Composite Structures. 51(5), pp. 607-610. 1994

https://doi.org/10.1016/0045-7949(94)90068-X

[13] Singh, M. P., Abdelnaser, S. "Random Response of Symmetric Cross-ply 'Composite Beams with Arbitrary Boundary Conditions." AIAA Journal, 30(4), pp. 1081-1088. 1992.

https://doi.org/10.2514/3.11030

[14] Vinson, J. R., Sierakowski, R. L., Bert, C. W. "The Behavior of Structures Composed of Composite Materials." Journal of Applied Mechanics. 51(1), p. 249. 1987. https://doi.org/10.1115/1.3172985

[15] Zhou, G. Y., Wang, Q. "Use of magnetorheological elastomer in an adaptive sandwich beam with conductive skins Part II: dynamic properties." International Journal of Solids and Structures. 43(17), pp. 5403-5420. 2006. https://doi.org/10.1016/j.ijsolstr.2005.07.044

\section{Appendix}

Strain energy for axial deformations

$U_{1}=\frac{1}{2} b \int_{0}^{l} \int_{-h / 2}^{-h / 2}\left[\epsilon_{x}^{0}+z k_{x}^{0}+z^{3} k_{x}^{2}\right]^{T}\left[Q_{11}\right]\left[\epsilon_{x}^{0}+z k_{x}^{0}+z^{3} k_{x}^{2}\right] d x d z$

$U_{1}=\frac{1}{2} b \int_{0}^{l} \int_{-h / 2}^{-h / 2}\left[\begin{array}{lll}\epsilon^{0} & k^{0} & k^{2}\end{array}\right]\left[\begin{array}{lll}A_{11} & B_{11} & E_{11} \\ B_{11} & D_{11} & F_{11} \\ E_{11} & F_{11} & H_{11}\end{array}\right]\left[\begin{array}{l}\epsilon^{0} \\ k^{0} \\ k^{2}\end{array}\right] d x$

Strain energy for transverse deformation

$U_{2}=\frac{1}{2} b \int_{0}^{l} \int_{-h / 2}^{h / 2}\left[\epsilon_{x z}^{0}+z^{2} k_{x z}^{2}\right]^{T}\left[\begin{array}{ll}Q_{55} & Q_{54} \\ Q_{45} & Q_{44}\end{array}\right]\left[\epsilon_{x z}^{0}+z^{2} k_{x z}^{2}\right] d x d z$

Stiffness Element matrix for top and bottom skin due to axial deformation

$$
\begin{gathered}
U=\frac{1}{2} b\left(\int_{0}^{l}\{d\}^{T}[B(x, y)]^{T}\left[\begin{array}{ccc}
A_{11} & B_{11} & E_{11} \\
B_{11} & D_{11} & F_{11} \\
E_{11} & F_{11} & H_{11}
\end{array}\right][B(x, y)] *\{d\}\right) d x \\
K_{e t, e b}=b\left(\int_{-a}^{a}\left[B_{t, b}(x, y)\right]^{T}\left[\begin{array}{lll}
A_{11} & B_{11} & E_{11} \\
B_{11} & D_{11} & F_{11} \\
E_{11} & F_{11} & H_{11}
\end{array}\right]\left[B_{t, b}(x, y)\right]\right) d x
\end{gathered}
$$

Stiffness Element matrix for top and bottom skin due to shear deformation

$$
k_{s}=b \int_{-a}^{a}\left[B_{s}(x, y)\right]^{T}\left[\begin{array}{ll}
A_{11}^{s} & D_{11}^{s} \\
D_{11}^{s} & F_{11}^{s}
\end{array}\right]\left[B_{s}(x, y)\right] d x
$$

Stiffness Element matrix for and core

$$
k_{c}=b \int_{-a}^{a}\left[B_{c}(x, y)\right]^{T}\left[G_{x z}\right]\left[B_{c}(x, y)\right] d x
$$


Strain displacement matrix for top skin due to axial deformation

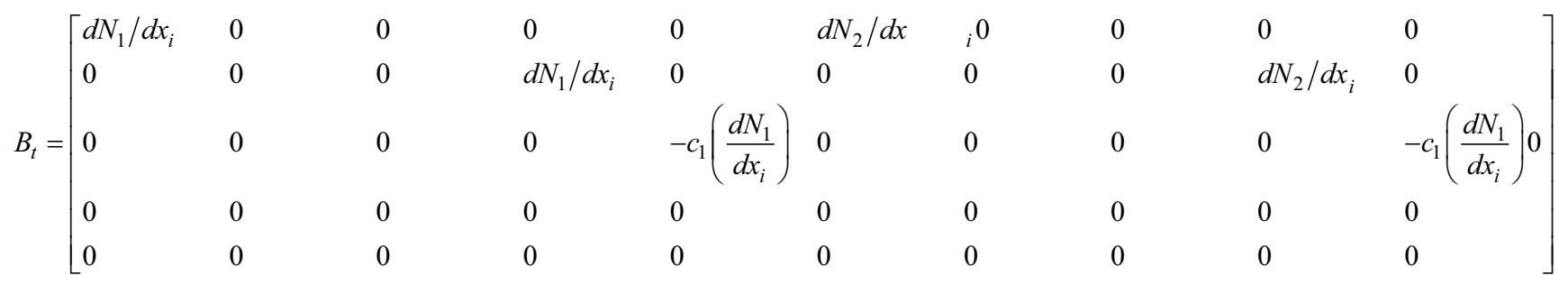

Strain displacement matrix for bottom skin due to axial deformation

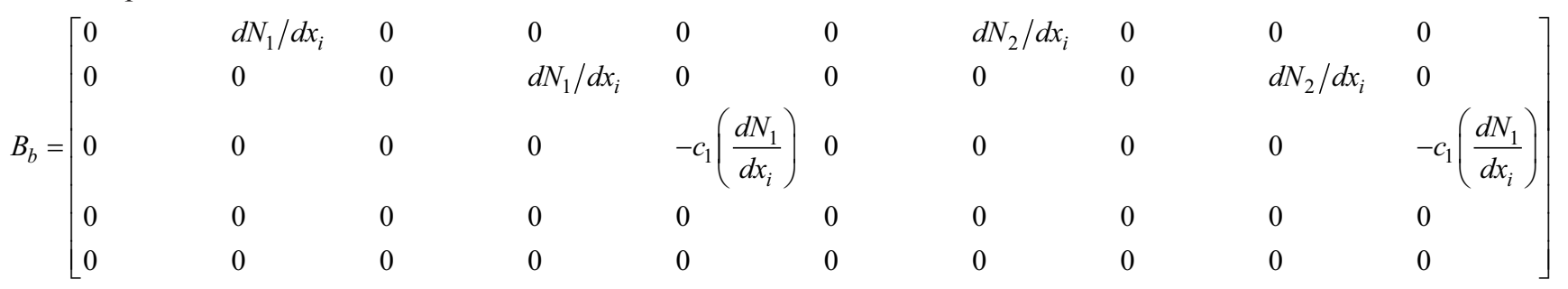

Strain displacement matrix for top and bottom skin due to transverse deformation

$$
B_{s}=\left[\begin{array}{llllllllll}
0 & 0 & 0 & 0 & 0 & 0 & 0 & 0 & 0 & 0 \\
0 & 0 & 0 & 0 & 0 & 0 & 0 & 0 & 0 & 0 \\
0 & 0 & 0 & 0 & 0 & 0 & 0 & 0 & 0 \\
0 & 0 & d N_{1} / d x_{i} & N_{1} & 0 & 0 & 0 & d N_{2} / d x_{i} & N_{2} & 0 \\
0 & 0 & 0 & 0 & -3 * C_{1} * N_{1} & 0 & 0 & 0 & 0 & -3 * C_{1} * N 2
\end{array}\right]
$$

Strain displacement matrix for core due to transverse deformation

$$
B_{C}=\left[\begin{array}{llllllllll}
0 & 0 & 0 & 0 & 0 & 0 & 0 & 0 & 0 & 0 \\
0 & 0 & 0 & 0 & 0 & 0 & 0 & 0 & 0 & 0 \\
0 & 0 & 0 & 0 & 0 & 0 & 0 & 0 & 0 & 0 \\
C_{1} N_{1} & C_{2} N_{1} & d N_{1} / d x_{i} & C_{3} N_{1} & C_{4} N_{1} & C_{1} N_{2} & C_{2} N_{2} & d N_{2} / d x_{i} & C_{3} N_{2} & C_{4} N_{2} \\
0 & 0 & 0 & 0 & 0 & 0 & 0 & 0 & 0 & 0
\end{array}\right]
$$

Mass matrix for top and bottom skin

$$
\begin{aligned}
& m_{e t}=b \int_{0}^{l} \sum\left[N_{i}(x, y)\right]^{T}[I]\left[N_{i}(x, y)\right] d x \\
& N=\left[\begin{array}{llllllllll}
N_{1} & 0 & 0 & 0 & 0 & N_{2} & 0 & 0 & 0 & 0 \\
0 & 0 & 0 & 0 & 0 & 0 & 0 & 0 & 0 & 0 \\
0 & 0 & N_{1} & 0 & 0 & 0 & 0 & N_{2} & 0 & 0 \\
0 & 0 & 0 & N_{1} & 0 & 0 & 0 & 0 & N_{2} & 0 \\
0 & 0 & 0 & 0 & N_{1} & 0 & 0 & 0 & 0 & N_{2}
\end{array}\right] \\
& m_{e b}=b \int_{0}^{l} \sum\left[\begin{array}{llllllllll}
\left.N_{i}(x, y)\right]^{T}[I]\left[N_{i}(x, y)\right. & 0 \\
0 & & & & & & & & \\
N & & & & & & & & & \\
0 & 0 & 0 & 0 & 0 & 0 & 0 & 0 & 0 & 0 \\
0 & N_{1} & 0 & 0 & 0 & 0 & N_{2} & 0 & 0 & 0 \\
0 & 0 & N_{1} & 0 & 0 & 0 & 0 & N_{2} & 0 & 0 \\
0 & 0 & 0 & N_{1} & 0 & 0 & 0 & 0 & N_{2} & 0 \\
0 & 0 & 0 & 0 & N_{1} & 0 & 0 & 0 & 0 & N_{2}
\end{array}\right]
\end{aligned}
$$


Mass matrix for core

$m_{c}=b \frac{h_{c}^{3}}{12} \int_{0}^{l} \sum N_{i}(x, y)^{T}[I] N_{i}(x, y) d x$

$N=\left[\begin{array}{llllllllll}0 & 0 & 0 & 0 & 0 & 0 & 0 & 0 & 0 & 0 \\ 0 & 0 & 0 & 0 & 0 & 0 & 0 & 0 & 0 & 0 \\ 0 & 0 & 0 & 0 & 0 & 0 & 0 & 0 & 0 & 0 \\ C_{1} N_{1} & C_{2} N_{1} & d N_{1} / d x_{i} & C_{3} N_{1} & C_{4} N_{1} & C_{1} N_{2} & C_{2} N_{2} & d N_{2} / d x_{i} & C_{3} N_{2} & C_{4} N_{2} \\ 0 & 0 & 0 & 0 & 0 & 0 & 0 & 0 & 0 & 0\end{array}\right]$

Where the constants:

$\mathrm{C}_{1}=1 / \mathrm{h}_{\mathrm{c}}$;

$\mathrm{C}_{2}=-1 / \mathrm{h}_{\mathrm{c}}$;

$\mathrm{C}_{3}=-\left(\mathrm{h}_{\mathrm{t}}+\mathrm{h}_{\mathrm{b}}\right) /\left(2 * \mathrm{~h}_{\mathrm{c}}\right) ;$

$\mathrm{C}_{4}=\left(\mathrm{h}_{\mathrm{t}}+\mathrm{h}_{\mathrm{b}}\right) /\left(6 * \mathrm{~h}_{\mathrm{c}}\right)$;

$m=$ mass; $v=$ velocity. 